\title{
CD24: A Rheostat That Modulates Cell Surface Receptor Signaling of Diverse Receptors
}

\author{
D. Craig Ayre and Sherri L. Christian* \\ Department of Biochemistry, Memorial University of Newfoundland, St. John's, NL, Canada
}

Keywords: CD24, signal transduction, protein interaction, cellular activation, surface receptor, GPI-anchored protein, extracellular stress signaling, receptor partner

\section{BACKGROUND}

CD24 (also called Heat Stable Antigen or nectadrin) is expressed on many cell types (Fang et al., 2010), and its expression is dynamically regulated during cellular differentiation (Ayre et al., 2016). CD24 was first described for its role in blocking B lymphocyte (B cell) development. Transgenic mice overexpressing CD24 and CD24 knockout mice exhibit a loss of immature B cells via their increased apoptosis (Hough et al., 1996; Nielsen et al., 1997) demonstrating that altering CD24 expression has serious repercussions in these cells. Additionally, antibody (Ab)-mediated engagement of CD24 induces apoptosis or suppresses proliferation of B cells, depending on their developmental stage (Chappel et al., 1996). CD24 also mediates homeostatic proliferation in T

\section{OPEN ACCESS}

Edited by:

Pedro M. Fernández-Salguero, University of Extremadura, Spain

Reviewed by:

Luisa Martinez-Pomares,

University of Nottingham, UK

*Correspondence:

Sherri L. Christian sherri.christian@mun.ca

Specialty section:

This article was submitted to Signaling,

a section of the journa Frontiers in Cell and Developmental

Biology

Received: 04 November 2016 Accepted: 09 December 2016 Published: 27 December 2016

Citation:

Ayre DC and Christian SL (2016) CD24: A Rheostat That Modulates Cell Surface Receptor Signaling of Diverse Receptors.

Front. Cell Dev. Biol. 4:146. doi: 10.3389/fcell.2016.00146 cells (Li et al., 2004), and can negatively regulate inflammation by inhibiting dendritic cell (DC) activation (Chen et al., 2009).

CD24 also acts outside the immune system. It supports the differentiation of immature preadipocytes into adipocytes (Rodeheffer et al., 2008; Fairbridge et al., 2015; Smith et al., 2015) and is a positive regulator of cerebellar neurite outgrowth, but a negative regulator for dorsal root ganglion neurogenesis (Kleene et al., 2001). In contrast, CD24 negatively regulates corneal growth to inhibit the development of pterygium (Riau et al., 2011). CD24 can regulate both pro- and antiproliferative effects in cancer cells, and both increase or reduce metastasis, depending on the cancer type (Kristiansen et al., 2004; Ju et al., 2011). Finally, we and others have identified CD24 as being carried on exosomes and microvesicles (Keller et al., 2007; Ayre et al., 2015; Grigor'eva et al., 2016), where its ultimate function is unknown.

CD24 has also been implicated in regulating cell stress. In a model of acetaminophen-induced liver damage, wild type mice regulated liver inflammation via CD24 and Siglec-G on DCs, whereas in CD24 knockout mice, the same challenge proved fatal (Chen et al., 2009). In addition, hypoxia in solid tumors induced CD24 expression via Hypoxia Inducible Factor-1 leading to increased tumor cell survival (Thomas et al., 2012). Finally, CD24 has been shown to regulate angiogenesis through Heat Shock Protein 90 and modulation of the STAT3/VEGF pathway (Wang et al., 2016). Therefore, CD24 is also important for modulating the sensitivity or cellular response to extracellular stresses.

CD24 is a glycophosphatidylinositol (GPI)-anchored protein, possessing no intracellular signaling domains (Kay et al., 1991). However, several signal transduction proteins are associated with CD24 activity. The best-described are the Src-family protein tyrosine kinases Lyn, Fyn, Fgr,

Abbreviations: Ab, Antibody; BCR, B Cell Receptor; CXCR4, C-X-C chemokine receptor type 4; DAMP, Danger Associated Molecular Pattern; DC, Dendritic Cell; GPI, Glycophosphatidylinositol; HMGB1, High Mobility Group Box 1; HNK-1, Human Natural Killer-1; L1CAM, L1 Cell Adhesion Molecule; MAPK, Mitogen Activated Protein Kinase; NCAM1, Neural Cell Adhesion Molecule; PTK, Protein Tyrosine Kinase; STAT3, Signal Transducer and Activator of Transcription 3; SDF1, Stromal Cell-Derived Factor 1; TLR, Toll-Like Receptor; VEGF, Vascular Endothelial Growth Factor. 
Lck and Hck but how these are activated is unknown (Sammar et al., 1997; Suzuki et al., 2001; Fang et al., 2010; Su et al., 2012). Many ligands have been identified for CD24 including P-, L-, and E- Selectin, High Mobility Group Box 1 (HMGB1), L1 cell adhesion molecule (L1CAM), Neural cell adhesion molecule (NCAM1) and Siglec-G (Aigner et al., 1995; Myung et al., 2011; Tan et al., 2016). To date, no mechanism has been proposed that explains the contradictory nature of the processes regulated by CD24, its apparent lack of intrinsic signaling capability, or its diverse collection of reported ligands.

\section{CD24 AS A SIGNALING RHEOSTAT}

Our opinion is that CD24 functions as a rheostat to modulate responses transduced by partnered cell surface receptor(s), and that these partners define the biological outcomes observed. Mechanistically, CD24 likely modulates activation of this partner through direct physical interaction mediated by its modifiable glycoslyations. The variable nature of CD24-mediated effects can thus be explained by its in cis association with unique, cell-type specific signaling partners (Figure 1A). The activity of the partner receptor could be further modulated through additional cis or trans elements acting via multi-receptor complexes. Moreover, the activity of the partner receptor could affect other downstream receptors. The presence or absence of CD24 may also alter the association of cell surface receptors with their canonical ligands, to promote or inhibit receptor activation. Similarly, direct ligation of CD24 could also affect its association and modulation of a partnered receptor. These ligand interactions could also promote association, or displacement, of CD24 from its receptor partner, which we term an associative or dissociative ligand, respectively.

While it is our opinion that this is the most logical explanation for the cell-specific effects mediated by CD24, it does not suggest a generalized mechanism for all GPI-anchored proteins. Others have been shown to work through specific transmembrane proteins, via endocytosis, or through lipid kinases (Kamen et al., 1988; Deckert et al., 1996; Stulnig et al., 1997; Horejsí et al., 1998; Suzuki et al., 2007; Paulick and Bertozzi, 2008), thus it is necessary to evaluate the mechanism of signaling for each GPI-anchored protein individually. Importantly, we believe that CD24 is unique in that it partners with different and, specific signaling receptors in a cell-type dependent manner.

\section{Supporting Rationale}

\section{Physical Interactions with Cell Surface Receptors}

CD24 interacts in cis with L1CAM on neuroblastoma cells in a predicted 5:1 ratio (Kadmon et al., 1995). L1CAM/CD24 complexes also associate in cis with NCAM1, forming a trimolecular complex, however no direct interaction between CD24 and NCAM1 was observed. The use of Ab against CD24 or L1CAM, to mimic ligand, induced a cellular calcium influx, with co-stimulation having a synergistic effect (Kadmon et al., 1995). This strongly suggests that the physical interaction between CD24 and L1CAM is associated with shared signaling processes.

CD24 also acts in cis with Siglec-G to moderate DC activation (Chen et al., 2009, 2011). In DC from the liver, CD24 forms a complex between Siglec-G and extracellular danger-associated molecular pattern (DAMP) proteins, such as HMGB1, to alter Toll-Like Receptor (TLR) activity (Chen et al., 2009; Liu et al., 2009). In the presence of CD24, Siglec-G inhibits the activation of TLRs by DAMPS. However, in the absence of CD24, the inhibition of TLR is lost. The interaction between CD24 and Siglec-G is facilitated by the glycosylations on CD24. Moreover, CD24 is a necessary mediator in this system as Siglec-G and HMGB1 are associative ligands of CD24, but neither HMGB1 nor TLR directly interacted with Siglec-G in this system (Chen et al., 2009).

\section{Other Interactions with Signaling Proteins and Receptors}

Studies in B cells showed that CD24 alters the localization of the B Cell Receptor (BCR) and associated intracellular signaling proteins within lipid rafts (Suzuki et al., 2001). Furthermore, engagement of the BCR or CD24 results in many of the same outcomes, including apoptosis, Protein Tyrosine Kinase (PTK) and Mitogen Activated Protein Kinase (MAPK) activity (Suzuki et al., 2001; Taguchi et al., 2003). Finally, co-ligation of CD24 and the BCR with sub-optimal doses of $\mathrm{Ab}$ can induce apoptosis, whereas ligation of either alone cannot, suggesting cooperative signaling (Suzuki et al., 2001).

CD24 is also important in regulating $\mathrm{T}$ cell survival. $\mathrm{T}$ cells must regulate their proliferation to support a long-lived cell population, but can expand their numbers during immune activation (Boyman et al., 2009). In the absence of CD24, homeostatic proliferation of T cells is markedly reduced, however immune-driven proliferation is less affected (Li et al., 2004), likely because it depends on TCR co-receptors (Chen and Flies, 2013). When CD24+ T cells are transferred to CD24-knockout mice, excessive and destructive homeostatic T cell proliferation occurs, but CD24 expressed on dendritic cells is sufficient to ameliorate this effect (Li et al., 2006). This suggests that CD24 can act in cis on the $\mathrm{T}$ cell to regulate TCR signaling, or in trans, where DC-expressed CD24 can bind and modulate its partner(s) on the $\mathrm{T}$ cell.

\section{Regulation of Plasma Membrane Organization and Signaling}

As CD24 lacks an intracellular domain, it cannot directly activate intracellular signaling pathways. CD24 is resident in cholesterolrich microdomains termed lipid rafts (Lingwood and Simons, 2010). In B cells and breast cancer cells CD24 excludes CXCR4, the receptor for Stromal Cell Derived Factor-1 (SDF-1), from lipid rafts whereas in the absence of CD24, CXCR4 can enter (Schabath et al., 2006). This exclusion prevents SDF-1-mediated CXCR4 signaling. In contrast, $\beta$-integrin is normally found in non-lipid raft membrane domains, but in the presence of CD24 it can translocate into lipid rafts (Runz et al., 2008) to promote cell-cell adhesion (Baumann et al., 2012). Therefore, these studies suggest that CD24 also regulates the physical location of surface receptors.

The ability of CD24 to act as a membrane-organizing factor further supports a role for $\mathrm{CD} 24$ to regulate receptor oligomerization and localization. Thus, it is possible that CD24 


\section{A}

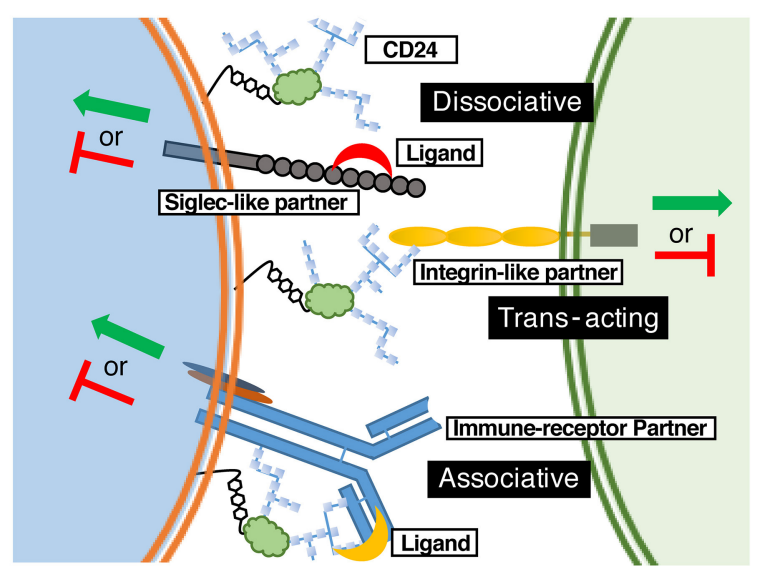

B

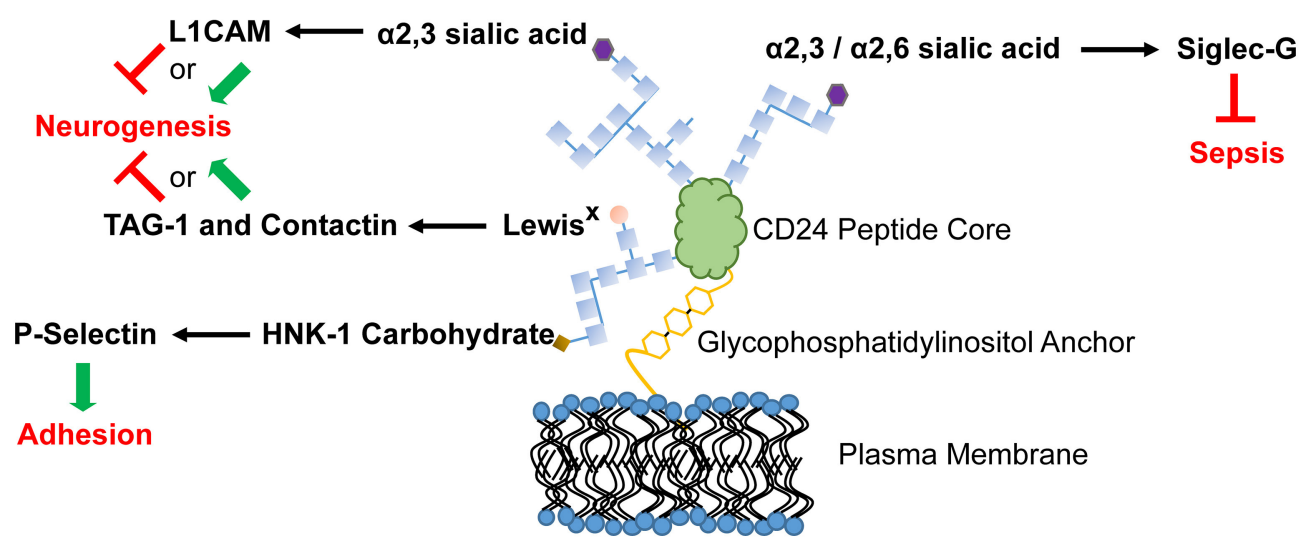

FIGURE 1 | CD24 operates through a combination of in cis and in trans partners to affect cell behavior in a cell-specific manner. (A) Schematic diagram showing the possible associations of CD24 with partner receptors and ligands. These associations selectively tune cellular responses. CD24 association with a signaling partner may be enhanced or inhibited through associative and dissociative ligands, respectively. The various CD24 interactions may not be mutually exclusive on a single cell, thus leading to a mosaic of cellular interactions and activation (green arrow) or inhibitory (red line) effects. (B) Interactions between specific CD24 glycosylations, ligands and known biological outcomes. Glycosylations are depicted as chains of carbohydrate monomers (blue squares) but do not represent a specific structure. The ligand-interacting, terminal carbohydrate moiety is indicated. L1CAM, Contactin and TAG-1 show both activating and inhibitory signals for neurogenesis as both effects can be mediated in discrete regions during CNS development.

can rapidly or contextually alter its associations, which may be another mechanism through which it exerts context-specific effects.

\section{IDENTIFYING CD24 MECHANISMS}

If CD24-mediated intracellular signaling depends on its association with cell-type specific surface receptors, identification of these partners is essential. In some cases, transcriptomic data may be used to predict partners by their co-expression with CD24 (Ayre et al., 2016), similar to the approach that identified novel ligand-receptor interactions regulating neuronal stem cell renewal (Yuzwa et al., 2016). Alternatively, identifying common signaling outcomes between CD24 and cell specific surface receptors could be used to predict receptor partners. For example, the common downstream signaling elicited by
CD24 and the BCR suggests they could partner directly or via another intermediate (Suzuki et al., 2001). Visualization of co-localized receptors through high resolution microscopy may be employed to demonstrate association on intact cells, such as was used to characterize epidermal growth factor-induced receptor dimerization (Winckler et al., 2013) Alternatively, if there are no known or predicted CD24 interactors expressed in cells of interest, non-biased proteomicsbased identification of CD24 interacting proteins could be used, like that used in the mass spectroscopy-based identification of N-methyl-d-aspartate receptor complexes (Husi et al., 2000).

Confirming the functional interactions between CD24 and its partner could be accomplished in vivo with the use of knockout and transgenic animals and in vitro using gene knockout or over-expression vectors, to alter the expression of CD24 and 
its putative signaling partner. Altering the expression of CD24 should disrupt the signaling through its partner. For example, if CD24 acts to restrict signaling, then the receptor partner may become hyper-responsive in a CD24 knockout, such as is observed with the negative regulation of the BCR by CD22 (O'Keefe et al., 1996). The inverse relationship would be seen if CD24 is a positive regulator of signaling. This relationship may explain the loss of developing B cells in both CD24 knockout and CD24-overexpressing mice, since the BCR can transduce pro-survival or pro-apoptotic signals, depending on $\mathrm{B}$ cell developmental status and the strength of BCR stimulation (Rajewsky, 1996; Chen et al., 1999). In CD24-knockout animals, the BCR may be over-sensitive leading to apoptosis, whereas in transgenic CD24 over-expressing mice, the BCR may no longer provide supportive tonic signaling, also leading to apoptosis.

With whole-body knockout animals, compensatory changes to the expression of the signaling partner may occur due to the absence of CD24, to re-establish their signaling potential. These changes may be observed by comparing the expression of partner receptors in wild type vs. CD24 knockout mice. The generation of inducible CD24 knock-out models, to prevent compensatory changes in partnered receptors or signaling pathways, would negate these concerns.

Importantly, knockdown or over-expression of the signaling partner would have the same biological outcomes as the loss or gain of $\mathrm{CD} 24$, respectively. In this case, CD24 could still be engaged with ligand or $\mathrm{Ab}$, but would not exert any effect in the absence of its partner.

Determining the mechanism for CD24-ligand specificity is also key. CD24 has been shown to vary in size from approximately 30 to $80 \mathrm{kDa}$, depending on the tissue from which it is isolated due to the variable mosaic of its $\mathrm{N}$ - and $\mathrm{O}$ - linked glycosylations (Fang et al., 2010). The different terminal glycans exhibit unique binding potential to cell surface receptors. For example, Siglec-G binds to $\alpha 2,6$ and $\alpha 2,3$ sialic acid (Chen et al., 2011), however L1CAM interacts with only the $\alpha 2,3$ form (Bleckmann et al., 2009; Figure 1B). Contactin and TAG-1 bind to Lewis ${ }^{\mathrm{X}}$ carbohydrates (Lieberoth et al., 2009) and P-selectin binds to human natural killer-1 (HNK-1) sulfated carbohydrates (Aigner et al., 1997; Figure 1B). If the binding and activity of CD24 is glycan-dependent, tissue-specific glycosylation would create glyco-variants of CD24 capable of interacting with specific partners, allow a selectivity of responsiveness, and preventing

\section{REFERENCES}

Aigner, S., Ruppert, M., Hubbe, M., Sammar, M., Sthoeger, Z., Butcher, E. C., et al. (1995). Heat stable antigen (mouse CD24) supports myeloid cell binding to endothelial and platelet P-selectin. Int. Immunol. 7, 1557-1565. doi: 10.1093/intimm/7.10.1557

Aigner, S., Sthoeger, Z. M., Fogel, M., Weber, E., Zarn, J., Ruppert, M., et al. (1997). CD24, a mucin-type glycoprotein, is a ligand for P-selectin on human tumor cells. Blood 89, 3385-3395.

Ayre, D. C., Elstner, M., Smith, N. C., Moores, E. S., Hogan, A. M., and Christian, S. L. (2015). Dynamic regulation of CD24 expression and release systemic effects. It is our opinion that future studies to identify in cis and in trans partners of CD24 should also identify the glycans on CD24 mediating those interactions.

\section{IMPLICATIONS AND CONCLUSIONS}

Unlocking the CD24 signaling mechanism may have wideranging implications in understanding the regulation of cell fate determination in normal and cancer cells. We suggest that CD24 influences different cis-interacting partners, or that some CD24 "ligands" may not directly interact with CD24, but with an associated partner. This would explain how CD24 is associated with numerous ligands and cellular activities but be widely expressed and evolutionarily conserved. As CD24 is also carried on extracellular vesicles, the ability to act in cis or in trans with many partners may be significant for its functions. As a regulator of cell signaling or stress, CD24-laden vesicles may be potent signaling modulators that can interact with numerous partners in the cellular microenvironment. In our opinion, the interaction of CD24 with different signaling partners in a cell-type specific manner is the most likely explanation for the diverse effects attributed to CD24. Overall, we believe that CD24 has a single function, acting as a rheostat to modulate signaling by receptor partners and fine-tune responses to extracellular stimuli.

\section{AUTHOR CONTRIBUTIONS}

DCA and SLC conceived the idea, and contributed equally to the preparation of the manuscript. DCA and SLC approved the final manuscript.

\section{FUNDING}

Funding provided by a Discovery Grant to SLC from the Natural Sciences and Engineering Research Council of Canada (4021522011). DCA is supported by a trainee award from the Beatrice Hunter Cancer Research Institute with funds provided by The Terry Fox Strategic Health Research Training Program in Cancer Research at CIHR and by Memorial University of Newfoundland.

\section{ACKNOWLEDGMENTS}

We thank Nikitha K. Pallegar for critical review of the manuscript. and Christian, S. L. (2016). Analysis of the structure, evolution, and expression of CD24, an important regulator of cell fate. Gene 590, 324-337. doi: 10.1016/j.gene.2016.05.038

Baumann, P., Thiele, W., Cremers, N., Muppala, S., Krachulec, J., Diefenbacher, M., et al. (2012). CD24 interacts with and promotes the activity of csrc within lipid rafts in breast cancer cells, thereby increasing integrindependent adhesion. Cell Mol. Life Sci. 69, 435-448. doi: 10.1007/s00018-0110756-9 
Bleckmann, C., Geyer, H., Lieberoth, A., Splittstoesser, F., Liu, Y., Feizi, T., et al. (2009). O-glycosylation pattern of CD24 from mouse brain. Biol. Chem. 390, 627-645. doi: 10.1515/BC.2009.044

Boyman, O., Létourneau, S., Krieg, C., and Sprent, J. (2009). Homeostatic proliferation and survival of naive and memory T cells. Eur. J. Immunol. 39, 2088-2094. doi: 10.1002/eji.200939444

Chappel, M. S., Hough, M. R., Mittel, A., Takei, F., Kay, R., and Humphries, K. (1996). Cross-linking the murine heat-stable antigen induces apoptosis in B cell precursors and suppresses the anti-CD40-induced proliferation of mature resting B lymphocytes. J. Exp. Med. 184, 1639-1649. doi: 10.1084/jem.184.5.1639

Chen, G. Y., Chen, X., King, S., Cavassani, K. A., Cheng, J., Zheng, X., et al. (2011). Amelioration of sepsis by inhibiting sialidase-mediated disruption of the CD24SiglecG interaction. Nat. Biotechnol. 29, 428-435. doi: 10.1038/nbt.1846

Chen, G. Y., Tang, J., Zheng, P., and Liu, Y. (2009). CD24 and Siglec-10 selectively repress tissue damage-induced immune responses. Science 323, 1722-1725. doi: $10.1126 /$ science. 1168988

Chen, L., and Flies, D. B. (2013). Molecular mechanisms of T cell co-stimulation and co-inhibition. Nat. Rev. Immunol. 13, 227-242. doi: 10.1038/nri3405

Chen, W., Wang, H. G., Srinivasula, S. M., Alnemri, E. S., and Cooper, N. R. (1999). $\mathrm{B}$ cell apoptosis triggered by antigen receptor ligation proceeds via a novel caspase-dependent pathway. J. Immunol. 163, 2483-2491.

Deckert, M., Ticchioni, M., and Bernard, A. (1996). Endocytosis of GPIanchored proteins in human lymphocytes: role of glycolipid-based domains, actin cytoskeleton, and protein kinases. J. Cell Biol. 133, 791-799. doi: $10.1083 /$ jcb.133.4.791

Fairbridge, N. A., Southall, T. M., Ayre, D. C., Komatsu, Y., Raquet, P. I., Brown, R. J., et al. (2015). Loss of CD24 in mice leads to metabolic dysfunctions and a reduction in white adipocyte tissue. PLOS ONE 10:e141966. doi: 10.1371/journal.pone.0141966

Fang, X., Zheng, P., Tang, J., and Liu, Y. (2010). CD24: from A to Z. Cell Mol. Immunol. 7, 100-103. doi: 10.1038/cmi.2009.119

Grigor'eva, A. E., Tamkovich, S. N., Eremina, A. V., Tupikin, A. E., Kabilov, M. R., Chernykh, V. V., et al. (2016). Characteristics of exosomes andmicroparticles discovered in human tears. Biomed Khim. 62, 99-106. doi: $10.18097 / \mathrm{pbmc} 20166201099$

Horejsí, V., Cebecauer, M., Cerný, J., Brdicka, T., Angelisová, P., and Drbal, K. (1998). Signal transduction in leucocytes via GPI-anchored proteins: an experimental artefact or an aspect of immunoreceptor function? Immunol. Lett. 63, 63-73. doi: 10.1016/S0165-2478(98)00054-6

Hough, M. R., Chappel, M. S., Sauvageau, G., Takei, F., Kay, R., and Humphries, K. (1996). Reduction of early B lymphocyte precursors in transgenic mice overexpressing the murine heat-stable antigen. J. Immunol. 156, 479-488.

Husi, H., Ward, M. A., Choudhary, J. S., Blackstock, W. P., Grant, S. G., et al. (2000). Proteomic analysis of NMDA receptor-adhesion protein signaling complexes. Nat. Neurosci. 3, 661-669. doi: 10.1038/76615

Ju, J. H., Jang, K., Lee, K. M., Kim, M., Kim, J., Yi, J., et al. (2011). CD24 enhances DNA damage-induced apoptosis by modulating NF-kappaB signaling in CD44-expressing breast cancer cells. Carcinogenesis 32, 1474-1483. doi: $10.1093 /$ carcin/bgr173

Kadmon, G., von Bohlen und Halbach, F., Horstkorte, R., Eckert, M., Altevogt, P., and Schachner, M. (1995). Evidence for cis interaction and cooperative signalling by the heat-stable antigen nectadrin (murine CD24) and the cell adhesion molecule L1 in neurons. Eur. J. Neurosci. 7, 993-1004. doi: 10.1111/j.1460-9568.1995.tb01087.x

Kamen, B. A., Wang, M. T., Streckfuss, A. J., Peryea, X., and Anderson, R. G. (1988). Delivery of folates to the cytoplasm of MA104 cells is mediated by a surface membrane receptor that recycles. J. Biol. Chem. 263, 13602-13609.

Kay, R., Rosten, P. M., and Humphries, R. K. (1991). CD24, a signal transducer modulating $\mathrm{B}$ cell activation responses, is a very short peptide with a glycosyl phosphatidylinositol membrane anchor. J. Immunol. 147, 1412-1416.

Keller, S., Rupp, C., Stoeck, A., Runz, S., Fogel, M., Lugert, S., et al. (2007). CD24 is a marker of exosomes secreted into urine and amniotic fluid. Kidney Int. 72, 1095-1102. doi: 10.1038/sj.ki.5002486

Kleene, R., Yang, H., Kutsche, M., and Schachner, M. (2001). The neural recognition molecule $\mathrm{L} 1$ is a sialic acid-binding lectin for $\mathrm{CD} 24$, which induces promotion and inhibition of neurite outgrowth. J. Biol. Chem. 276, 21656-21663. doi: 10.1074/jbc.M101790200
Kristiansen, G., Sammar, M., and Altevogt, P. (2004). Tumour biological aspects of CD24, a mucin-like adhesion molecule. J. Mol. Histol. 35, 255-262. doi: 10.1023/B:HIJO.0000032357.16261.c5

Li, O., Chang, X., Zhang, H., Kocak, E., Ding, C., Zheng, P., et al. (2006). Massive and destructive $\mathrm{T}$ cell response to homeostatic cue in CD24-deficient lymphopenic hosts. J. Exp. Med. 203, 1713-1720. doi: 10.1084/jem.20052293

Li, O., Zheng, P., and Liu, Y. (2004). CD24 expression on T cells is required for optimal T cell proliferation in lymphopenic host. J. Exp. Med. 200, 1083-1089. doi: 10.1084/jem.20040779

Lieberoth, A., Splittstoesser, F., Katagihallimath, N., Jakovcevski, I., Loers, G., Ranscht, B., et al. (2009). Lewis(x) and alpha2,3-sialyl glycans and their receptors TAG-1, Contactin, and L1 mediate CD24-dependent neurite outgrowth. J. Neurosci. 29, 6677-6690. doi: 10.1523/JNEUROSCI.4361-08.2009

Lingwood, D., and Simons, K. (2010). Lipid rafts as a membrane-organizing principle. Science 327, 46-50. doi: 10.1126/science.1174621

Liu, Y., Chen, G. Y., and Zheng, P. (2009). CD24-Siglec G/10 discriminates dangerfrom pathogen-associated molecular patterns. Trends Immunol. 30, 557-561. doi: 10.1016/j.it.2009.09.006

Myung, J. H., Gajjar, K. A., Pearson, R. M., Launiere, C. A., Eddington, D. T., and Hong, S. (2011). Direct measurements on CD24-mediated rolling of human breast cancer MCF-7 cells on E-selectin. Anal. Chem. 83, 1078-1083. doi: 10.1021/ac102901e

Nielsen, P. J., Lorenz, B., Müller, A. M., Wenger, R. H., Brombacher, F., Simon, M., et al. (1997). Altered erythrocytes and a leaky block in B-cell development in CD24/HSA-deficient mice. Blood 89, 1058-1067.

O'Keefe, T. L., Williams, G. T., Davies, S. L., and Neuberger, M. S. (1996). Hyperresponsive B cells in CD22-deficient mice. Science 274, 798-801. doi: 10.1126/science.274.5288.798

Paulick, M. G., and Bertozzi, C. R. (2008). The glycosylphosphatidylinositol anchor: a complex membrane-anchoring structure for proteins. Biochemistry 47, 6991-7000. doi: 10.1021/bi8006324

Rajewsky, K. (1996). Clonal selection and learning in the antibody system. Nature 381, 751-758. doi: 10.1038/381751a0

Riau, A. K., Wong, T. T., Lan, W., Finger, S. N., Chaurasia, S. S., Hou, A. H., et al. (2011). Aberrant DNA methylation of matrix remodeling and cell adhesion related genes in pterygium. PLoS ONE 6:e14687. doi: 10.1371/journal.pone. 0014687

Rodeheffer, M. S., Birsoy, K., and Friedman, J. M. (2008). Identification of white adipocyte progenitor cells in vivo. Cell 135, 240-249. doi: 10.1016/j.cell.2008. 09.036

Runz, S., Mierke, C. T., Joumaa, S., Behrens, J., Fabry, B., and Altevogt, P. (2008). CD24 induces localization of betal integrin to lipid raft domains. Biochem. Biophys. Res. Commun. 365, 35-41. doi: 10.1016/j.bbrc.2007.10.139

Sammar, M., Gulbins, E., Hilbert, K., Lang, F., and Altevogt, P. (1997). Mouse CD24 as a signaling molecule for integrin-mediated cell binding: functional and physical association with src-kinases. Biochem. Biophys. Res. Commun. 234, 330-334. doi: 10.1006/bbrc.1997.6639

Schabath, H., Runz, S., Joumaa, S., and Altevogt, P. (2006). CD24 affects CXCR4 function in pre-B lymphocytes and breast carcinoma cells. J. Cell Sci. 119, 314-325. doi: 10.1242/jcs.02741

Smith, N. C., Fairbridge, N. A., Pallegar, N. K., and Christian, S. L. (2015). Dynamic upregulation of CD24 in pre-adipocytes promotes adipogenesis. Adipocyte 4, 89-100. doi: 10.4161/21623945.2014.985015

Stulnig, T. M., Berger, M., Sigmund, T., Stockinger, H., Horejsí, V., and Waldhäusl, W. (1997). Signal transduction via glycosyl phosphatidylinositol-anchored proteins in T cells is inhibited by lowering cellular cholesterol. J. Biol. Chem. 272, 19242-19247. doi: 10.1074/jbc.272.31.19242

Su, N., Peng, L., Xia, B., Zhao, Y., Xu, A., Wang, J., et al. (2012). Lyn is involved in CD24-induced ERK1/2 activation in colorectal cancer. Mol. Cancer 11:43. doi: 10.1186/1476-4598-11-43

Suzuki, K. G., Fujiwara, T. K., Edidin, M., and Kusumi, A. (2007). Dynamic recruitment of phospholipase $\mathrm{C}$ gamma at transiently immobilized GPIanchored receptor clusters induces IP3-Ca ${ }^{2+}$ signaling: single-molecule tracking study 2. J. Cell Biol. 177, 731-742. doi: 10.1083/jcb.200609175

Suzuki, T., Kiyokawa, N., Taguchi, T., Sekino, T., Katagiri, Y. U., and Fujimoto, J. (2001). CD24 Induces apoptosis in human B cells via the glycolipidenriched membrane domains/rafts-mediated signaling system. J. Immunol. 166, 5567-5577. doi: 10.4049/jimmunol.166.9.5567 
Taguchi, T., Kiyokawa, N., Mimori, H., Suzuki, T., Sekino, T., Nakajima, H., et al. (2003). Pre-B cell antigen receptor-mediated signal inhibits CD24-induced apoptosis in human pre-B cells. J. Immunol. 170, 252-260. doi: 10.4049/jimmunol.170.1.252

Tan, Y., Zhao, M., Xiang, B., Chang, C., and Lu, Q. (2016). CD24: from a hematopoietic differentiation antigen to a genetic risk factor for multiple autoimmune diseases. Clin. Rev. Allergy. Immunol. 50, 70-83. doi: 10.1007/ s12016-015-8470-2

Thomas, S., Harding, M. A., Smith, S. C., Overdevest, J. B., Nitz, M. D., Frierson, H. F., et al. (2012). CD24 is an effector of HIF-1-driven primary tumor growth and metastasis. Cancer Res. 72, 5600-5612. doi: 10.1158/0008-5472.CAN-11-3666

Wang, X., Zhang, Y., Zhao, Y., Liang, Y., Xiang, C., Zhou, H., et al. (2016). CD24 promoted cancer cell angiogenesis via Hsp90-mediated STAT3/VEGF signaling pathway in colorectal cancer. Oncotarget 7, 55663-55676. doi: 10.18632/oncotarget.10971.

Winckler, P., Lartigue, L., Giannone, G., De Giorgi, F., Ichas, F., Sibarita, J. B., et al. (2013). Identification and super-resolution imaging of ligand- activated receptor dimers in live cells. Sci Rep. 3:2387. doi: 10.1038/srep 02387

Yuzwa, S. A., Yang, G., Borrett, M. J., Clarke, G., Cancino, G. I., Zahr, S. K., et al. (2016). Proneurogenic ligands defined by modeling developing cortex growth factor communication networks. Neuron 91, 988-1004. doi: 10.1016/j.neuron.2016.07.037

Conflict of Interest Statement: The authors declare that the research was conducted in the absence of any commercial or financial relationships that could be construed as a potential conflict of interest.

Copyright (๑) 2016 Ayre and Christian. This is an open-access article distributed under the terms of the Creative Commons Attribution License (CC BY). The use, distribution or reproduction in other forums is permitted, provided the original author(s) or licensor are credited and that the original publication in this journal is cited, in accordance with accepted academic practice. No use, distribution or reproduction is permitted which does not comply with these terms. 